\title{
Studi Komparatif Program Pengendalian Hama Terpadu Terhadap Pengetahuan, Produksi, Dan Pendapatan Petani Padi Sawah Di Kabupaten Labuhanbatu Utara
}

\section{Comparative Study of Integrated Pest Management Program Knowledge, Production, and Income of Rice Field Farmers in North Labuhanbatu Regency}

\author{
Baratuj Zakiyah' ${ }^{1)}$, Retno Astuti K.2), Rahmanta Ginting3) \\ 1)Program Studi Magister Agribisnis, Pascasarjana, Universitas Medan Area, Indonesia \\ 2) Magister Agribisnis, Pascasarjana, Universitas Medan Area, Indonesia \\ 2) Departemen Agribisnis, Fakultas Pertanian, Universitas Sumatera Utara, Indonesia
}

\begin{abstract}
Abstrak
Penelitian ini bertujuan untuk mengetahui peranan program SLPHT dalam menambah pengetahuan petani dan untuk menganalisis perbedaan produktivitas serta pendapatan padi sawah di daerah petani lulusan SLPHT dengan petani non SLPHT di Kabupaten Labuhanbatu Utara. Penelitian menggunakan metode survey dan dilaksanakan di Kabupaten Labuhanbatu Utara selama 3 (tiga) bulan, mulai bulan April 2016 s.d. bulan Juni 2016. Jumlah sampel penelitian sebanyak 150 petani padi sawah dianalisis secara statistik menggunakan analisis uji beda rata-rata (T test analysis) menggunakan software SPPS versi 19. Hasil penelitian yaitu daerah dengan petani lulusan SLPHT produktivitas padi sawah rata-rata yaitu sebesar 4,74 Ton/Hektar/Musim Tanam (Ton/Ha/MT). Tidak ada perbedaan produksi dan pendapatan yang signifikan antara petani lulusan SLPHT dengan non SLPHT. Akan tetapi, terdapat selisih produksi antara keduanya sebesar $500 \mathrm{Kilogram} / \mathrm{Ha} / \mathrm{MT}$. Artinya daerah dengan petani lulusan SLPHT mempunyai produksi padi sawah lebih tinggi sebesar 500 $\mathrm{Kg} / \mathrm{Ha} / \mathrm{MT}$. Hasil dari analisis statistic secara rata-rata pendapatan petani lulusan SLPHT jauh lebih besar Rp. 1.060.113 daripada petani non SLPHT. Hasil riset ini juga menemukan bahwa program SLPHT dapat menambah wawasan pengetahuan petani dalam bidang pertanian.

Kata kunci: Padi Sawah, Program SLPHT, Pengetahuan, Produksi, Pendapatan
\end{abstract}

\begin{abstract}
This study aims to understand the role of the SLPHT program in increasing farmers' knowledge and for the analysis of income and rice income in farmers collecting SLPHT with non-SLPHT farmers in North Labuhanbatu Regency. The study used a survey method and was carried out in North Labuhanbatu Regency for 3 (three) months, starting in April 2016 until June 2016. The number of research samples were 150 lowland rice farmers analyzed using statistics using average difference analysis (T test analysis) using SPPS software version 19. Results of research conducted with farmers who developed SLPHT, lowland rice, average prices average of 4,74 tons / hectare / planting season (tons / ha / MT). There is no significant difference in production and income between farmers collecting SLPHT and non-SLPHT. However, there is a difference in production between 500 Kilograms / Ha / MT. Regional related to farmers. SLPHT has a higher paddy production of $500 \mathrm{~kg} / \mathrm{ha} / \mathrm{MT}$. The results of statistical analysis, average, average, income, farmers, SLPHT, much greater Rp. 1,060,113 from non-SLPHT farmers. The results of this study also found that the SLPHT program could broaden farmers' perspectives in agriculture.
\end{abstract}

Keywords: Lowland Rice, Integrated Pest Management Program, Knowledge, Production, Income

How to Cite: Zakiyah, B., R.A. Kuswardani dan R. Ginting. (2019). Studi Komparatif Program Pengendalian Hama Terpadu Terhadap Pengetahuan, Produksi, Dan Pendapatan Petani Padi Sawah Di Kabupaten Labuhanbatu Utara. Jurnal Ilmiah Magister Agribisnis, 1(1) 2019: 38-46,

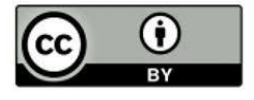


Zakiyah, B., R.A. Kuswardani dan R. Ginting. Studi Komparatif Program Pengendalian Hama Terpadu Terhadap Pengetahuan, Produksi, Dan Pendapatan Petani Padi Sawah Di Kabupaten Labuhanbatu Utara

\section{${ }^{*}$ E-mail: retnaastuti@uma.ac.id \\ PENDAHULUAN \\ ISSN 2550-1305 (Online)}

Salah satu tujuan pembangunan pertanian adalah untuk menciptakan ketahanan pangan dan peningkatan kesejahteraan petani, sehingga pemerintah mempunyai kewajiban untuk selalu memberikan support yang mendukung produktifitas petani melalui berbagai langkah kebijakan. Disamping itu, dalam rangka peningkatan kesejahteraan petani, diupayakan agar harga jual padi berada dalam tingkat yang mampu memberikan keuntungan bagi petani.

Usahatani adalah ilmu yang mempelajari tentang cara petani mengelola input atau faktor-faktor produksi (tanah, tenaga kerja, modal, teknologi, pupuk, benih, dan pestisida) dengan efektif, efisien, dan kontinyu untuk menghasilkan produksi yang tinggi sehingga pendapatan usahataninya meningkat. Adapun pengertian usahatani lainnya dapat dilihat dari masing-masing pendapat sebagai berikut. Prasetya (2006) menyatakan usahatani adalah ilmu yang mempelajari norma-norma yang dapat dipergunakan untuk mengatur usahatani sedemikian rupa sehingga dapat diperoleh pendapatan setinggitingginya. Sementara menurut Daniel (2010) usahatani adalah ilmu yang mempelajari cara-cara petani untuk mengkombinasikan dan mengoperasikan berbagai faktor-faktor produksi (tanah, tenaga kerja, modal dan manajemen) serta bagaimana petani memilih jenis dan besarnya cabang usahatani berupa tanaman atau ternak yang dapat memberikan pendapatan yang sebesar-besarnya dan secara kontinyu.

Menurut Soekartawi (2002) dalam Canny Widyastusti (2010), usahatani biasa diartikan sebagai ilmu yang mempelajari bagaimana seseorang mengalokasikan sumberdaya yang ada secara efektif dan efisien untuk tujuan memperoleh keuntungan yang tinggi pada waktu tertentu. Dikatakan efektif bila petani dapat mengalokasikan sumberdaya yang mereka miliki (kuasai) sebaik-baiknya, dan dikatakan efisien bila pemanfaatan sumberdaya tersebut menghasilkan keluaran (output). Tersedianya sarana atau faktor produksi (input) belum berarti produktifitas yang diperoleh petani akan tinggi. Namun bagaimana petani melakukan usahanya secara efisien adalah upaya yang sangat penting. Efisiensi teknis akan tercapai bila petani mampu mengalokasikan faktor produksi sedemikian rupa sehingga produksi tinggi tercapai. Bila petani mendapat keuntungan besar dalam usahataninya dikatakan bahwa alokasi faktor produksi efisien secara alokatif. Cara ini dapat ditempuh dengan membeli faktor produksi pada harga murah dan menjual hasil pada harga relatif tinggi. Bila petani mampu meningkatkan produksinya dengan harga sarana produksi dapat ditekan tetapi harga jual tinggi, maka petani tersebut melakukan efisiensi teknis dan efisiensi harga atau melakukan efisiensi ekonomi.

Padi merupakan salah satu komoditi pangan yang sangat dibutuhkan karena merupakan sumber bahan pangan utama masyarakat Indonesia. Oleh karena itu, semua elemen bangsa harus menjadikan kondisi tersebut sebagai titik tolak atau momentum untuk melakukan introspeksi dalam memperkuat ketahanan pangan nasional. Kebutuhan berupa bahan pangan utama khususnya beras semakin tahun akan semakin meningkat sesuai dengan laju pertumbuhan penduduk dan perkembangan kondisi perekonomian masyarakat. Hal ini akan mendorong petani untuk melakukan inovasi 
inovasi dan penerapan teknologi teknologi untuk mengefisiensikan usahatani padi mereka.

Penerapan teknologi pertanian seperti penggunaan benih unggul bermutu dan penggunaan pupuk yang berimbang juga telah banyak membantu meningkatkan hasil pertanian. Namun di sisi lain organisasi petani (kelompok tani) sebagian besar nampaknya kurang mampu untuk menghimpun dana/modal untuk dapat memenuhi kebutuhannya dalam berusahatani, khususnya dalam penyediaan sarana produksi yang tepat jumlah dan tepat waktu.

Konsep pengendalian hama terpadu sebagai gerakan pendekatan teknologi produksi pertanian berwawasan lingkungan muncul karena kegagalan cara pengendalian hama konvensional yang pada intinya mencoba menyederhanakan masalah perlindungan tanaman yaitu dengan menggunakan bahan kimiawi. Pengendalian kimiawi menimbulkan masalah baru resistensi hama, resurjensi, terbunuhnya musuh alami, terbunuhnya jasad bukan sasaran dan pencemaran.

Sejak pestisida digunakan secara besar-besaran dalam pengendalian hama dan pengendalian vector penyakit manusia, para pakar telah melaporkan berbagai dampak negatif pestisida bagi kesehatan manusia dan lingkungan hidup. Setiap jenis pestisida memiliki resiko bahaya bagi kesehatan dan lingkungan hidup meskipun tidak semua kelompok atau jenis pestisida memiliki resiko yang sama (Kasumbogo Untung, 2015). Pengguunaan pestisida secara berlebihan malah dapat memberikan dampak kerusakan struktur lingkungan dan ekosistem alami areal pertanaman.

Konsep Pengendalian Hama Terpadu (PHT) merupakan pilihan yang tepat untuk menjawab delamatis tersebut, karena PHT bertujuan untuk membatasi penggunaan pestisida sedikit mungkin, tetapi sasaran kualitas dan kuantitas produksi masih dapat dicapai. Berdasarkan data pengendalian organisme pengganggu tanaman (POPT/PHP) di wilayah Kabupaten Labuhanbatu Utara walaupun PHT sudah dilaksanakan sering terjadi serangan hama yang sulit diatasi pada lahan sawah milik petani, banyak ditemukan petani yang tidak memahami dan mengetahui pola budidaya tanaman sehat, masih banyak petani yang tidak mengetahui bagaimana cara melakukan pengendalian hama tanaman padi secara baik atau yang dikenal dengan Pengendalian Hama Terpadu (PHT).

SLPHT merupakan paket teknologi yang ramah lingkungan dan diharapkan dapat meningkatkan kesejahteraan petani padi sawah di Kabupaten Labuhanbatu Utara dibandingkan dengan petani yang belum menerapkan SLPHT. Terjadinya perbedaan terhadap produksi antara petani yang sudah menerapkan SLPHT dan petani yang belum menerapkan SLPHT, selain itu terjadinya penurunan biaya produksi khususnya penggunaan peralatan dan bahan pemberantasan hama dan penyakit sehingga melalui SLPHT dimungkinkan petani akan meningkatkan kesejahteraannya. Berdasarkan uraian latar belakang di atas maka penulis merasa penting dan tertarik untuk meneliti tentang pengaruh implementasi program pengendalian hama terpadu terhadap pengetahuan, produksi dan pendapatan petani padi di Kabupaten Labuhanbatu Utara.

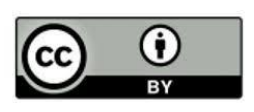


Zakiyah, B., R.A. Kuswardani dan R. Ginting. Studi Komparatif Program Pengendalian Hama Terpadu Terhadap Pengetahuan, Produksi, Dan Pendapatan Petani Padi Sawah Di Kabupaten Labuhanbatu Utara

\section{METODE PENELITIAN}

Pemilihan lokasi penelitian dilakukan secara sengaja (purposive). Dasar pemilihan kecamatan sampel yaitu kabupaten Labuhanbatu Utara terdiri dari total 8 (delapan) kecamatan yang berada didaerah tersebut. Dari 8 (delapan) kecamatan tersebut hanya ada 6 (enam) kecamatan yang dijadikan sampel karena memiliki usahatani padi sawah dengan pembagian 3 (tiga) kecamatan kontrol yaitu kecamatan yang telah mengikuti SLPHT dan 3 (tiga) kecamatan pembanding yaitu kecamatan yang belum mengikuti SLPHT. Penelitian dilaksanakan selama 3 (tiga) bulan, mulai bulan Juni 2016 s.d. bulan Agustus tahun 2016. Bentuk penelitian ini adalah observasi (survey) dan pengamatan di lapangan. Analisis data yang digunakan yaitu analisis deskriptif dan kuantitatif. Analisis deskriptif untuk menggambarkan karakteristik petani sampel. Analisis kuantitatif untuk mengetahui produksi, biaya produksi dan pendapatan usahatani padi sawah.

Populasi dalam penelitian ini adalah 150 petani padi sawah yang tersebar 25 orang di masing-masing kecamatan sebagai kontrol yaitu Aek Natas, Kualuh Selatan, dan Kualuh Hulu sedangkan 25 orang di masing-masing kecamatan pembanding yang belum mengikuti SLPHT yaitu Kualuh Leidong, Kualuh Hilir, dan Na IX-X.

Selain data primer yang diperoleh dari kuisioner dan wawancara responden, juga digunakan data sekunder dari instansi terkait meliputi BPS Pusat, BPS Labuhanbatu Utara, Dinas Pertanian dan Kantor Kecamatan setempat dengan menggunakan metode dokumentasi.

Analisis deskriptif digunakan untuk mengambarkan dan menggali sosial ekonomi dengan membuat karakteristik petani padi sawah. Analisis deskriptif menggunakan tabel frekuensi yaitu penyajian data dan informasi dalam bentuk tabel sederhana yang berisi pengelompokan jawaban yang sama. Tabel frekuensi berfungsi untuk mengambarkan ciri-ciri atau karakteristik dari suatu variabel (Rangkuti, 1997). Hasil yang diperoleh diolah dengan menggunakan presentase berdasarkan jumlah responden.

Presentase terbesar dari setiap hasil adalah faktor dominan dari masing-masing variabel yang dianalisis. Pengelompokan karakteristik konsumen meliputi data demografi seperti usia, jenis kelamin, pekerjaan, pendidikan, dan tingkat pendapatan serta jumlah tanggungan.

Pendapatan usahatani dianalisis dengan menggunakan analisis pendapatan usahatani, dengan model perhitungan total pendapatan dikurangi dengan total biaya produksi. Untuk keperluan analisis maka data yang dikumpulkan di lapangan selanjutnya direkap dengan membuat tabulasi sesuai dengan kebutuhan analisis data. Untuk menguji besarnya pendapatan usahatani padi sawah digunakan rumus sebagai berikut:

a. Analisis Biaya Produksi

$$
\mathrm{TC}=\mathrm{FC}+\mathrm{VC}
$$

Dimana; $\quad$ TC : Total Cost (total biaya) (Rp/Ha/MT)

FC : Fixed Cost (biaya tetap) (Rp/Ha/MT) 
b. Pendapatan Kotor Usahatani

$$
\text { VC : Variable Cost (biaya tidak tetap) (Rp/Ha/MT) }
$$

$\mathrm{TR}=\mathrm{Q} \times \mathrm{P}$ Dimana :

$\mathrm{TR}=$ Pendapatan Kotor $(\mathrm{Rp} / \mathrm{Ha} / \mathrm{MT})$

$\mathrm{Q}=$ Produksi Padi $(\mathrm{Kg} / \mathrm{Ha} / \mathrm{MT})^{\prime}$

$\mathrm{P}=$ Harga Padi $(\mathrm{Rp} / \mathrm{Kg})$

c. Pendapatan Bersih Usahatani

$\mathrm{Pd}=\mathrm{TR}-\mathrm{TC}$

Dimana: $\quad P d=$ Pendapatan Bersih (Rp/Bulan)

$\mathrm{TR}=$ Pendapatan Kotor (Rp/Bulan)

$\mathrm{TC}=$ Total Biaya $(\mathrm{Rp} /$ Bulan$)$

Data dari hasil penelitian diolah dengan alat analisis independent sample-t test dengan bantuan software SPSS versi 19. Independent sample-t test untuk menguji perbedaan produksi dan pendapatan petani padi sawah pada sampel kontrol dan sampel pembanding.

Formulasinya sebagai berikut :

$$
\begin{aligned}
& t=\frac{\bar{x}_{1}-\bar{x}_{2}}{S \sqrt{\frac{1}{n_{1}}+\frac{1}{n_{2}}}} \\
& \text { dengan, } \\
& S^{2}=\frac{\left(n_{1}-1\right) S_{1}{ }^{2}+\left(n_{2}-1\right) S_{2}{ }^{2}}{n_{1}+n_{2}-2}
\end{aligned}
$$

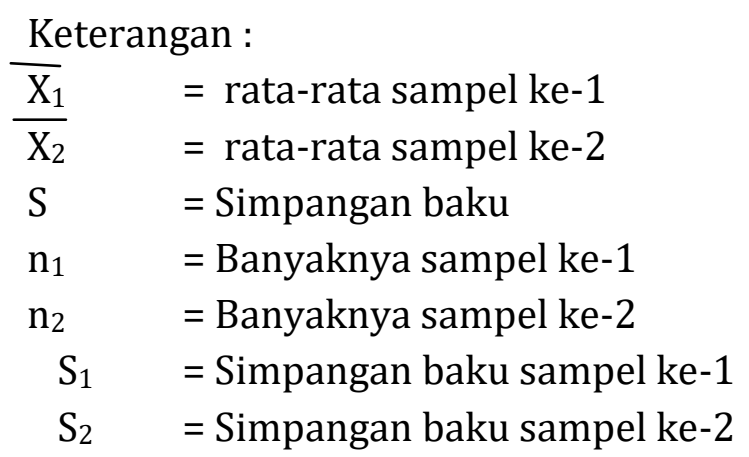

(Sugiyono, 2010: 237)

Independent sample-t test digunakan untuk menentukan apakah 2 (dua) sampel yang tidak berhubungan memiliki nilai rata-rata yang berbeda. Independent sample-t test dilakukan dengan cara membandingkan perbedaan antara dua nilai rata-rata dengan standart error dari perbedaan rata-rata dua sampel. Standart error perbedaan dalam nilai rata-rata terdistribusi secara normal. Dapat disimpulkan bahwa Independent sample-t test adalah membandingkan rata-rata dua grup yang tidak berhubungan satu dengan yang lainnya. Kriteria penilaian hipotesis yang diajukan adalah :

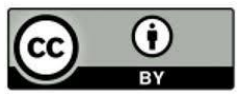


Zakiyah, B., R.A. Kuswardani dan R. Ginting. Studi Komparatif Program Pengendalian Hama Terpadu Terhadap Pengetahuan, Produksi, Dan Pendapatan Petani Padi Sawah Di Kabupaten Labuhanbatu Utara

Ho; tidak ada perbedaan signifikan antara biaya produksi, produksi dan pendapatan petani padi sawah yang mengikuti SLPHT dengan yang tidak mengikuti SLPHT di Kabupaten Labuhanbatu Utara.

Ha: ada perbedaan signifikan antara biaya produksi, produksi dan pendapatan petani padi sawah yang mengikuti SLPHT dengan yang tidak mengikuti SLPHT di Kabupaten Labuhanbatu Utara.

Untuk mengukur tingkat pengetahuan petani, maka penelitian ini menggunakan angket dengan jawaban terstruktur yang nantinya akan diberikan kepada sampel petani yang telah mengikuti SLPHT. Indikator dari pengetahuan dikembangkan berdasarkan teori yang dikemukakan oleh Soekidjo Notoatmodjo yaitu Pengalaman, Keyakinan dan Sumber informasi.

Untuk indikator keyakinan dan sumber informasi berisikan pertanyaan dengan kriteria jawaban "Ya" dan "Tidak", dengan skor jawaban Ya $=2$ dan skor jawaban Tidak = 1 . Sedangkan untuk indikator pengalaman menggunakan parameter pengukuran berdasarkan pedoman pelaksanaan sekolah lapangan hama terpadu. Dengan ketentuan kriteria lebih dari 4 adalah tinggi dan kurang atau sama dengan 4 kriteria rendah, berikut skor dihitung intervalnya :

Skor Maksimal $=$ Jumlah Indikator $\times$ Skor Maksimal $=3 \times 2=6$

Skor Minimal = Jumlah Indikator $\mathrm{x}$ Skor Minimal $=3 \times 1=3$

Rentang Skor/ Range $\quad=6-3=3$

$$
\text { Interval }=\frac{\text { Range }}{\text { Banyak Kriteria }}=\frac{3}{2}=1,5 \quad \begin{aligned}
& \text { Parameter Penilaian }= \\
& \text { Total Skor Maksimum } \\
& \text { Interval }
\end{aligned}=\frac{6}{1,5}=
$$

\section{HASIL DAN PEMBAHASAN}

Karakteristik petani sampel yang mengikuti SLPHT dan yang tidak mengikuti SLPHT luas lahan sawah yang ditanami padi sawah petani sampel yaitu antara 0,26 hektar sampai 1 hektar, umur petani sampel SLPHT didominasi oleh kisaran usia 46 sampai 55 tahun, tingkat pendidikan didomnasi oleh lulusan SLTP.

Rata-rata pengunaan pestisida pada usahatani padi sawah sampel SLPHT sebesar 3,67 liter pestisida untuk satu hektar lahan padi sawah, sedangkan petani yang tidak mengikuti SLPHT dapat menghabiskan 14,47 liter untuk satu hektar lahan padi sawah. Petani sampel yang tidak mengikuti SLPHT cenderung menggunakan pestisida kimiawi secara besar karena tidak berpedoman kepada pemakaian pestisida yang ideal sesuai dengan tingkat serangan/ ambang batas serangan, dan kebutuhan dilapangan.

Minimnya pengetahuan mereka ditambah dengan kecemasan atas serangan hama mengakibatkan mereka hanya berpedoman kepada feeling dan berasumsi bahwa semakin banyak menggunakan pestisida maka akan semakin baik dalam menanggulangi serangan hama tanpa memperhitungkan resistansi hama, atau kerusakan ekosistem akibat pemakaian pestisida yang berlebihan.

Produksi petani yang mengikuti program SLPHT dengan yang tidak mengikuti SLPHT tidak memiliki perbedaan signifikan jika diuji dengan uji beda sampel independen t-test/ komparatif statistik. Namun, secara deskriptif statistik, produksi petani yang mengikuti program SLPHT jauh lebih tinggi jika dibandingkan dengan petani yang tidak 
mengikuti SLPHT dengan selisih rata-rata produksi kedua kelompok petani tersebut adalah $500 \mathrm{Kg} / \mathrm{Ha} / \mathrm{MT}$. Artinya sampel petani yang mengikuti program SLPHT memiliki produksi yang lebih tinggi $500 \mathrm{Kg} / \mathrm{Ha} / \mathrm{MT}$ daripada petani sampel non SLPHT.

Penggunaan total biaya produksi usahatani padi sawah antara petani yang mengikuti program SLPHT dengan yang tidak mengikuti SLPHT memiliki perbedaan yang sangat signifikan berdasarkan uji hipotesis dengan statistik komparatif/ uji ttest, maupun statistik deskriptif dengan melihat perbandingan nilai rata-rata total biaya produksi. Dari hasil uji t-test/Levene memiliki nilai F sebesar 106,131 dengan signifikan sebesar 0,000. Oleh karena probabilitas $0,000<$ dari 0,05 dikatakan varians untuk kedua sampel berbeda, artinya $\mathrm{H}_{a}$ / hipotesis awal diterima/ ada perbedaan yang signifikan dari total biaya usahatani padi sawah untuk kedua sampel penelitian. Total biaya produksi usahatani padi sawah Petani yang mengikuti program SLPHT jauh lebih rendah dibandingkan dengan petani yang tidak mengikuti SLPHT dengan selisih rata-rata total biaya produksi usahatani padi sawah kedua kelompok petani tersebut sebesar Rp. 1.060.113 Rp/Ha/MT. Sampel petani SLPHT mampu menekan biaya produksi usahatani sebesar Rp. 1.060.113.

Pendapatan bersih usahatani padi sawah antara petani yang mengikuti program SLPHT dengan yang tidak mengikuti SLPHT tidak memiliki perbedaan yang signifikan berdasarkan komparatif deskriptif dengan uj-it test untuk sampel penelitian. Meskipun demikian, secara deskriptif statistik dengan membandingkan nilai ratarata kedua sampel tersebut, pendapatan bersih sampel petani yang mengikuti SLPHT lebih tinggi daripada sampel petani yang tidak mengikuti SLPHT. Selisih rata-rata pendapatan bersih kedua kelompok sampel tersebut adalah Rp. 3.468.060 Rp/Ha/MT.

Rata-rata skor jawaban responden yang mengikuti SLPHT berada pada 4 lebih artinya berada dalam criteria tinggi yang artinya mereka setuju bahwa program SLPHT dapat meningkatkan pengetahuan mereka dalam mengelola lahan pertanian padi sawah.

Hasil dari penelitian ini sama dan didukung oleh kondisi/ fakta lapangan dan hasil pengamatan Dinas Pertanian Kabupaten Labuhanbatu Utara, bahwasannya secara kuantitas produksi panen, program SLPHT mampu meningkatkan hasil panen petani rata-rata sebesar $500 \mathrm{Kg} / \mathrm{Ha}$, menekan biaya usahatani dan meningkatkan pendapatan petani padi sawah, meskipun secara statistik komparatif dengan membandingkan sampel Non SLPHT pencapaian-pencapaian ini belum dikatakan cukup signifikan.

\section{SIMPULAN}

Produksi petani yang mengikuti program SLPHT jauh lebih tinggi jika dibandingkan dengan petani yang tidak mengikuti SLPHT. Total biaya produksi usahatani padi sawah Petani yang mengikuti program SLPHT jauh lebih rendah dibandingkan dengan petani yang tidak mengikuti SLPHT. Pendapatan bersih sampel petani yang mengikuti SLPHT lebih tinggi daripada sampel petani yang tidak mengikuti SLPHT. Rata-rata skor jawaban responden yang mengikuti SLPHT berada dalam criteria tinggi yang artinya mereka setuju bahwa program SLPHT dapat meningkatkan pengetahuan mereka dalam

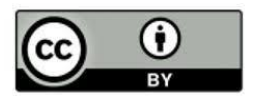


Zakiyah, B., R.A. Kuswardani dan R. Ginting. Studi Komparatif Program Pengendalian Hama Terpadu Terhadap Pengetahuan, Produksi, Dan Pendapatan Petani Padi Sawah Di Kabupaten Labuhanbatu Utara

mengelola lahan pertanian padi sawah, khususnya bagaimana menerapkan sistem pengendalian hama terpadu agar tercipta system pertanian yang ramah lingkungan dan berkesinambungan.

Disarankan program SLPHT dapat diselenggarakan secara menyeluruh di Kabupaten Labuhanbatu Utara sehingga program SLPHT dapat meningkatkan produktivitas padi sawah di Kabupaten Labuhanbatu Utara yang pada akhirnya meningkatkan kesejahteraan petani dan mendukung suksesnya program ketahanan pangan oleh pemerintah. Disarankan agar dilakukan monitoring oleh dinas terkait yang melaksanakannya. Pertemuan-pertemuan kelompok tani SLPHT harus digiatkan untuk menumbuhkan kembali optimisme petani SLPHT dalam menjalankan sistem pertanian dengan pengendalian hama terpadu yang berkesinambungan dan berwawasan lingkungan. Perlu diadakan penelitian lanjutan tentang kinerja para penyuluh program SLPHT agar diperoleh hasil pembanding sehingga dapat dijadikan bahan pertimbangan pengambilan yang tepat berkenaan dengan pelaksanaan program SLPHT di Kabupaten Labuhanbatu Utara.

\section{DAFTAR PUSTAKA}

Alexander, M. (1977). Soil Microbiology, Second Edition. John Wiley and Sons, Ind., New York.

Apple, J. L. dan R. F. Smith. (1976). Integrated Pest Management, Plenum Press, New York and London.

Baehaki, Suherlan Effendi. (2010). Strategi Pengendalian Hama Terpadu Tanaman Padi Dalam Perspektif Praktek Pertanian Yang Baik (Good Agricultural Practies). Jurnal Penelitian Pengembangan Inovasi Pertanian, Balai Besar Penelitian Tanaman Padi, Subang. Tidak dipublikasikan secara umum.

Cahyono, W. (2008). Evaluasi Program SLPHT Tanaman Padi Di Kelompok Tani Sari Asih Desa Mayang Kecamatan Gatak Kabupaten Sukoharjo, Universitas Sebelas Maret, Surakarta.

Canny Widyastuti. (2010). Pelaksanaan SLPTT Padi Dalam Kegiatan PTT di Kecamatan Karang Pandan Kabupaten Karanganyar, Skripsi Universitas Sebelas Maret. Tidak dipublikasikan secara umum.

Daniel, Moeha R. (2010), Pengantar Ekonomi Pertanian. Bumi Aksara, Jakarta.

Hasibuan Nurliana. (2011). Perbandingan Model Pembelajaran Problem Posing Dan Model Kooperatif Tipe CIRC (Cooperative Integrated Reading And Compotition) Terhadap Hasil Belajar Ekonomi Siswa Kelas X SMA Mamiyai Al - Ittihadiyah Medan, Skripsi Universitas Muhammadiyah Sumatera Utara. Tidak dipublikasikan secara umum.

Hernanto, F. (2010). Ilmu Usahatani. Penebar Swadaya, Jakarta.

Hendarsih, S. dan N. Widiarta. Integrasi Sistem Pengendalian Hama Terpadu ke Dalam Model Pengelolaan Tanaman Terpadu. Avaliable at : http://www.202.158.78.120/publicatio n/wr254.035.pdf.25(4):13. Diakses tanggal 21 Juni 2015.

Kasumbogo Untung. (2015). Pengantar Pengelolaan Hama Terpadu (Edisi -2). Gadjah Mada University Press. Yogyakarta.

Mei Tri Sundari. (2011). Analisis Biaya Dan Pendapatan Usaha Tani Wortel Di Kabupaten Karanganyar. Jurnal SEPA, Vol. 7 No. 2 Februari 2011. UNS. Tidak dipublikasikan secara umum.

Metcalf, R. L. and W. H. Luckman. (1982). Introduction to Pest Management. Wiley Intersci Publish Moustiuer John of Metz Wiley and Sons, New York.

Nila Sari, Anna Fatchiya dan Prabowo Tjitropranoto. (2016). Tingkat Penerapan Pengendalian Hama Terpadu (PHT) Sayuran di

Kenagarian Koto Tinggi, Kabupaten Agam, Sumatera Barat. Jurnal Penyuluhan Pertanian, Vol. 12 No.1 Universitas Andalas, Padang. Tidak dipublikasikan secara umum.

Putong, Iskandar. (2010) . Pengantar Ekonomi Mikro dan Makro. Edisi Kedua. Penerbit Ghalia Indonesia. Jakarta.

Prasetya, B.H. dan Suriadikarta, D.A. (2006). Karakteristik, Potensi dan Teknologi Pengelolaan Tanah Ultisol untuk Pengembangan Pertanian Lahan Kering di Indonesia. Balai Besar 
Penelitian dan Pengembangan Sumberdaya Lahan Pertanian, Balai Penelitian Tanah. http://pustaka.litbang .deptan.go.id/publikasi.pdf

Rahim, A dan Hastuti, D.Retno. (2010). Ekonomi Pertanian: Teori dan Aplikasi. State University of Makasar Press.

Said. E. G. (2010). Dampak Negatif Pestisida, Sebuah Catatan Bagi Kita Semua. Available at : http://www.libraryusu.ac.id/module.ph p?Agrotek,Vol.2(1):71-72. Diakses tanggal 15 Februari 2011.

Smith and Allen. (1954). IPM Applies Ecological Principles to The Control of Pests, Smithburg.

Smith and Reynold. (1966). Principles, definitions and Scope of Integrated Pest Control. Proc. FAO Symposium on Integrated Pest Control.

Stern, VM, et. al. (1959). The Integrated Control Concepts, Hilgardia.

Siegel, S. (1990). Non Parametric Statistical for Social Experience and Research, PT. Gramedia, Jakarta.

Sugiyono, (2010). Metode Penelitian Bisnis, Alfabeta Cetakan 15, Bandung.

Suharjono. (2011). Dampak Implementasi Sekolah Lapangan Pengendalian Hama Terpadu Padi Terhadap Penggunaan Pestisida di Kabupaten Jember. Jurnal Penelitian Agrivor Volume 4. No. 1 Politeknik Negeri Jember. Tidak dipublikasikan secara umum.

Tambunan, T., (2010). Perkembangan Sektor Pertanian di Indonesia: Beberapa Isu Penting. Ghalia Indonesia. Jakarta.

Van Den Bosch, R. P. S. Messenger and A. P. Guitierrez, (1973). An Introduction to Biological Control, Plenum Press, New York and London. 